\title{
Coalbed Methane Extraction and Soil Suitability Concerns in the Powder River Basin, Montana and Wyoming
}

The Powder River Basin and

\section{Coalbed Methane}

The Powder River Basin is located in northeastern Wyoming and southeastern Montana. It is an area of approximately $55,000 \mathrm{~km}^{2}$ that is underlain by many coal seams. The basin extends over $400 \mathrm{~km}$ from Douglas, Wyoming, in the south to Forsyth, Montana, in the north (fig. 1). Extraction of methane gas from the coal seams that underlie the Powder River Basin began in Wyoming in the late 1980s and in Montana in the late 1990s.

Methane gas accumulates naturally within coal beds. Water in the coal beds provides the necessary pressure to keep the gas confined within the coal. Hydrostatic pressure from the water (called "co-produced water") must be reduced before gas can be brought to the surface. Management of co-produced water is a concern because of the large volumes of water involved and because of the composition of the water.

\section{Water Management Strategies}

About 100-200 barrels of coproduced water per day are being extracted from each active well in the Powder River Basin, which comes to over 1.5 million barrels of water per day for all the active coalbed methane wells in the Basin. Lab testing indicates that Powder River Basin co-produced water is potable but is high in sodium and other salts, especially in the western and northern parts of the Powder River Basin. Common water management strategies include discharge into drainages, stock

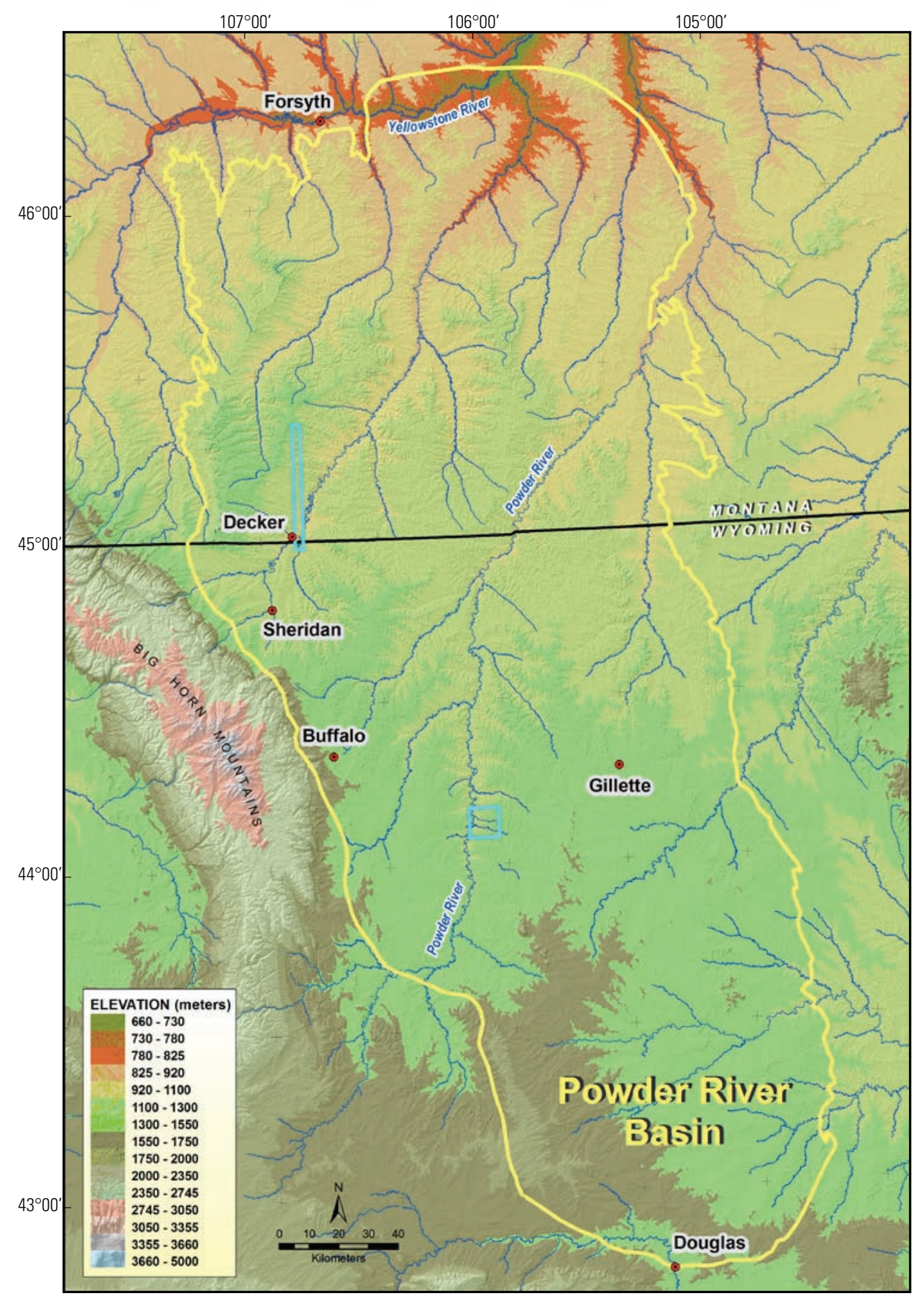

Figure 1. The outline of the Powder River Basin of Wyoming and Montana is shown on a color shaded relief map of the region. The blue outlines indicate locations of hyperspectral remote sensing data acquired by the Rocky Mountain Geographic Science Center. 
ponds, evaporation ponds, or infiltration ponds; treatment to remove sodium; or application of the water directly on the land surface via irrigation equipment or atomizers (fig. 2). Re-injecting the co-produced water back into the ground is a less common water management strategy because it requires locating a geologic unit with enough capacity to store the water.

\section{Geographic Science Focus-Use of Remote Sensing Technology to Locate Areas Unsuitable for the Land Application Water Management Strategy}

The direct land application water management strategy employed by some well operators involves using irrigation equipment or atomizers to spray co-produced water on the ground, in some cases in an attempt to grow crops (fig. 2). Problems may arise because much of the Powder River Basin contains soils with high amounts of swelling clays. Swelling clays are clays that expand when wet. Soils dominated by these clays can turn to hard pan if irrigated with water high in sodium, such as that extracted from coal seams in the Powder River Basin. Applying high-sodium water directly on an area composed of swelling clays will cause the ground surface to become almost impermeable to rain or irrigation water, thereby destroying any salt-intolerant vegetation in the area. Resource and land managers need data on the suitability of soils in the Powder River Basin, including the location of surficial swelling clays, to help them determine whether to permit the direct application of sodium-dominated co-produced water.

As part of the USGS Rocky Mountain Geographic Science Center's hyperspectral research program, researchers are investigating whether hyperspectral remote sensing data can be beneficial in locating areas of swelling clays. Materials on the Earth's surface reflect, absorb, and transmit solar radiation differently. Hyperspectral sensors have the ability to measure this energy across a broad spectral range that includes non-visible portions of the spectrum. We can identify materials on the Earth's surface by their signature of reflection or absorption at different wavelengths. Figure 3 shows the reflectance signature of the swelling clay montmorillonite.

Using detailed hyperspectral data collected over parts of the Powder River Basin (figs. 1 and 4) and applying our knowledge of how the clays of interest reflect energy, we will attempt to identify and map areas of swelling clays. If successful, such information will be useful to resource and land managers.

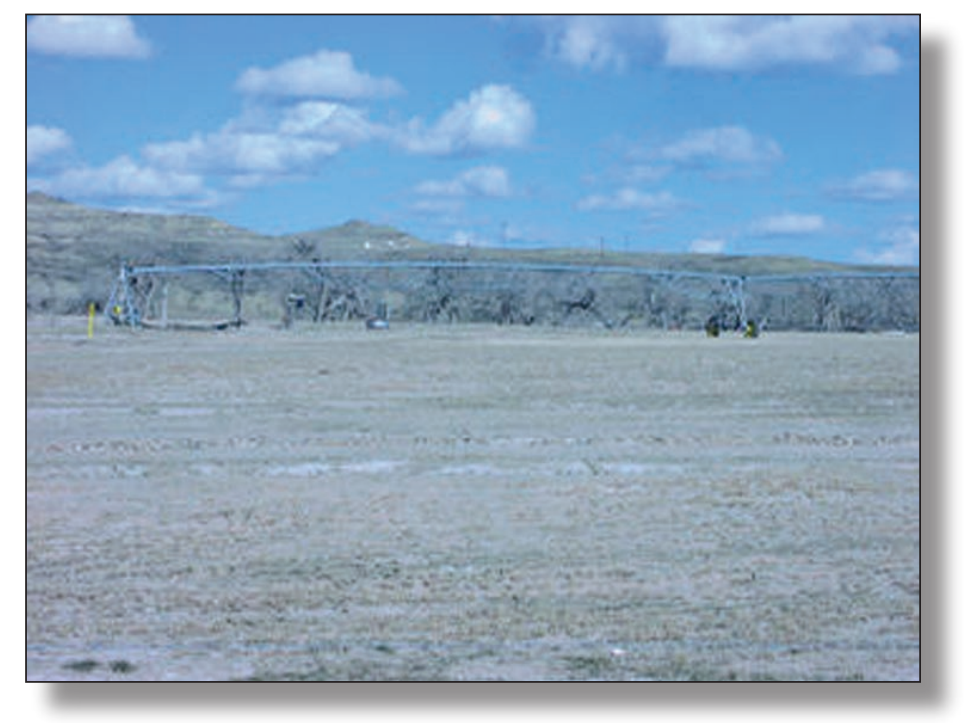

Figure 2. Center-pivot irrigation activity near Beaver Creek, Powder River Basin, Wyoming.

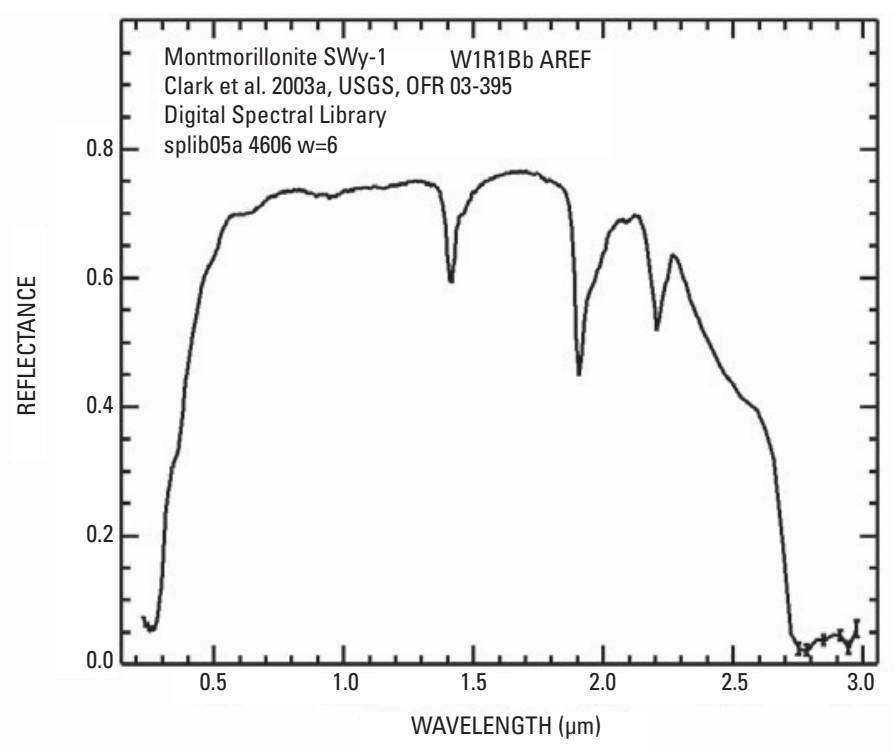

Figure 3. Relative energy reflected by the swelling clay montmorillonite. Taken from R.N. Clark, G.A. Swayze, R. Wise, K.E. Livo, T.M. Hoefen, R.F. Kokaly, and S.J. Sutley, USGS Digital Spectral Library splib05a, USGS Open File Report 03-395, 2003. 


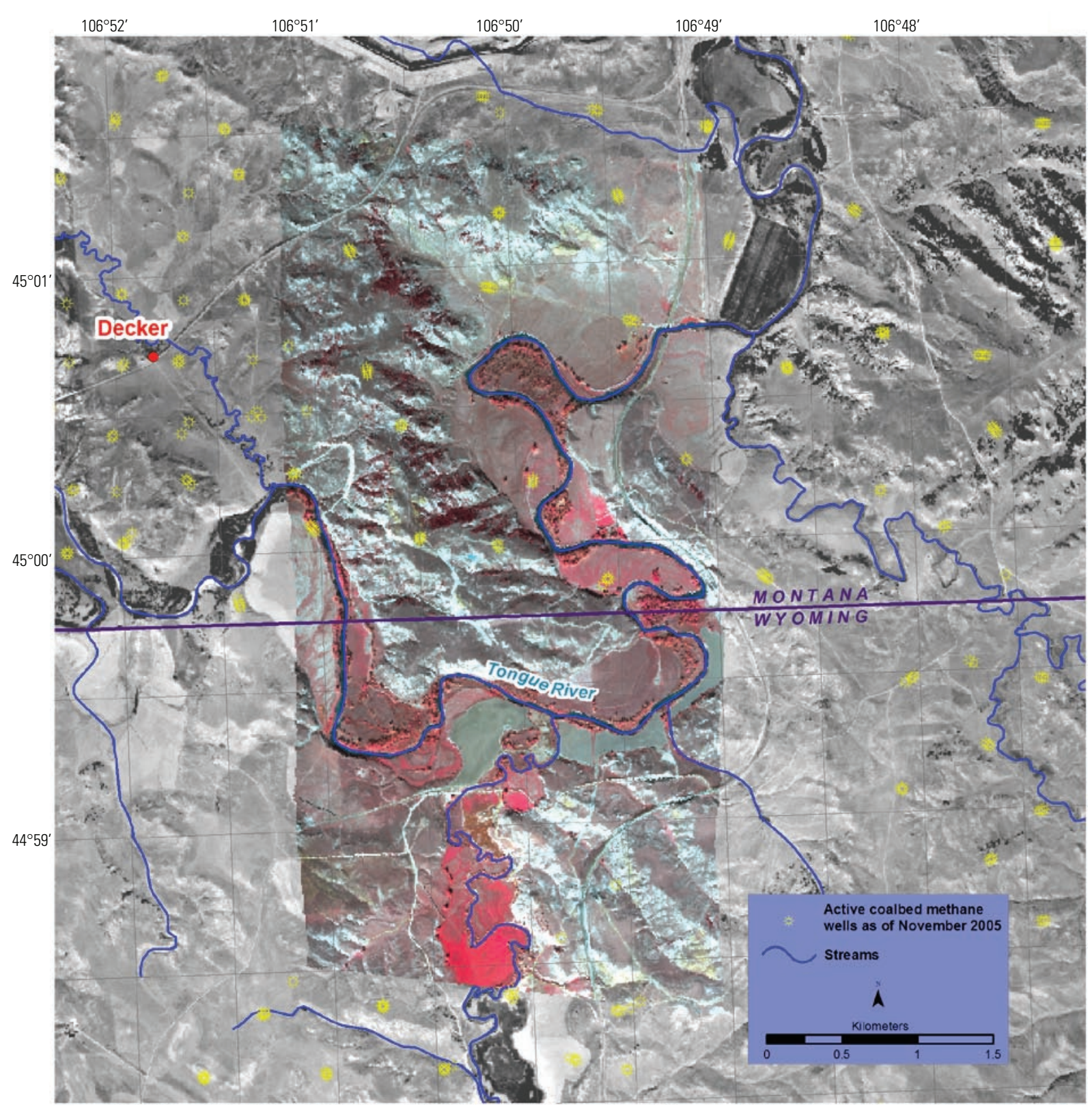

Figure 4. Color infrared image generated from the southern part of a hyperspectral flight line near Decker, Montana, overlaid on a black and white Digital Orthophoto Quadrangle. This area in southeastern Montana is an area of coalbed methane (CBM) activity. Yellow symbols indicate the locations of active coalbed methane wells in the area as of November 2005. Red areas on the color infrared image indicate healthy vegetation. Monitoring of vegetation surrounding CBM wells could provide resource and land managers early indications of problems caused by application of co-produced water. See figure 1 for the entire extent of this flight line.

\section{Contact:}

Jamie L. McBeth

U.S. Geological Survey

Rocky Mountain Geographic Science Center

P.O. Box 173492

Montana State University, 229 AJM Johnson Hall

Bozeman, MT 59717

e-mail: jlmcbeth@usgs.gov 